\title{
Low-temperature heat capacities of molybdenum diselenide and ditelluride *
}

\author{
HARMAS L. KIWIA and EDGAR F. WESTRUM, JR. \\ Department of Chemistry, University of Michigan, Ann Arbor, \\ Michigan 48104, U.S.A.
}

(Received 28 October 1974; in revised form 17 January 1975)

\begin{abstract}
The low-temperature heat capacities of $\mathrm{MoSe}_{2}$ and $\mathrm{MoTe}_{2}$ have been determined for technological and scientific reasons. Both compounds in their hexagonal form have a lamellar sandwich-layer structure and in confirmation of extant data on molybdenite, $\mathrm{MoS}_{2}$, these compounds are shown to follow the Debye limiting law for heat capacity at low temperature despite contrary indications in the literature. At $298.15 \mathrm{~K}$ the heat capacity $C_{p}$, entropy $S^{\circ}$, and Gibbs energy in the form $\left\{G^{\circ}(T)-H^{\circ}(0)\right\} / T$ are (for $\mathrm{MoSe}_{2}$ ) 16.87, 21.29, and $-10.33 \mathrm{cal}_{\mathrm{th}} \mathrm{K}^{-1} \mathrm{~mol}^{-1}$; and (for $\mathrm{MoTe}_{2}$ ) 18.38, 27.55, and -14.60 $\mathrm{cal}_{\mathrm{th}} \mathrm{K}^{-1} \mathrm{~mol}^{-1}$.
\end{abstract}

\section{Introduction}

Molybdenum is among the fission products produced in highest yield in nuclear reactors and the thermodynamics of its chalcogenide compounds is, therefore, important in the technology of fuel elements and coolant systems in nuclear reactors. Moreover, the chalcogenide compounds are used as high-temperature lubricants. Since a contrary finding existed in the literature as to the temperature dependence of the heat capacity of molybdenite prior to our recently published study, ${ }^{(1)}$ additional confirmation was a desideratum. Although the ultimate conformity of $\mathrm{MoS}_{2}$ with the Debye limiting-law heat-capacity behavior has been demonstrated, it was considered worthwhile to show that this was no accident of relative atomic masses or other artifacts but obtained as well for the similarly structured selenide and telluride compounds. All three hexagonal lattices possess a lamellar sandwich-layer type structure and taken together involve a four-fold range of relative atomic masses.

\section{APPARATUS}

\section{Experimental}

Heat capacity measurements were made in the Mark II adiabatic cryostat which has been described previously. ${ }^{(2)}$ The samples were contained in a gold-plated copper

a This work initiated under the Division of Research of the U.S. Atomic Energy Commission, project AT(11-1)-1149 and supported since May 1972 by the National Science Foundation, contract no. NSF GP-33424X, is based on a dissertation submitted to the H. H. Rackham School of Graduate Studies at the University of Michigan in partial fulfillment of the requirements for the Ph.D. degree by $H$. L. Kiwia under the auspices of a Rockefeller Foundation Scholarship.

- To whom correspondence concerning this paper should be addressed. 
calorimeter (laboratory designation W-48), incorporated a gold-gasketed seal, gold-plated copper vanes to enhance conductivity, a mass of $33.4657 \mathrm{~g}$, and an internal volume of $44.44 \mathrm{~cm}^{3}$. To facilitate rapid thermal equilibration, small amounts of helium gas (about 70 Torr) were introduced. $\dagger$ The temperature of the calorimeter was measured with a platinum capsule-type $25 \Omega$ (nominal) resistance thermometer (laboratory designation A-5) inserted into a re-entrant well in the calorimeter after calibration by the National Bureau of Standards. The resultant temperature scale was judged to correspond to the IPTS-68 to within $0.03 \mathrm{~K}$ from 10 to $90 \mathrm{~K}$ and within $0.04 \mathrm{~K}$ from 90 to $350 \mathrm{~K}$. A $150 \Omega$ constantan heater wound (non-inductively) on a cylindrical gold-plated copper heater core surrounds the resistance thermometer.

The chalcogenides ( $\mathrm{MoSe}_{2}, \mathrm{MoTe}_{2}$ ) were loaded directly into the calorimeter, since they are stable in air at room temperatures. The calorimeter within a stainlesssteel vessel connected to a high-vacuum line was evacuated, a small amount of helium gas was introduced to aid thermal equilibration, and then the calorimeter was sealed by forcing the gold gasket with a screw closure, against the knife-edged aperture (approximately $1 \mathrm{~cm}$ in diameter) on the calorimeter. The calorimeter seal was then tested for tightness in situ. It was then brought to constant mass (subject to room temperature, atmospheric pressure, and relative humidity adjustments) and Apiezon-T grease was added in quantity equal to that present during the separate heat-capacity determinations of the calorimeter + heater + thermometer assembly.

The masses, molar masses, densities, and helium gas pressures used for both chalcogenides are summarized in table 1. Heat-capacity measurements were made

TABLE 1. $\mathrm{MoS}_{2}$ and MoTe $\mathrm{H}_{2}$ sample details: molar mass $M$, sample mass $m$, density $\rho$, and helium pressure $p(\mathrm{He})$

$($ Torr $=101325 / 760) \mathrm{Pa}$

\begin{tabular}{ccccc}
\hline Compound & $M / \mathrm{g} \mathrm{mol}^{-1}$ & $m / \mathrm{g}$ & $\rho / \mathrm{g} \mathrm{cm}^{-3}$ & $p($ He)/Torr \\
\hline $\mathrm{MoSe}_{2}$ & 253.86 & 100.2236 & $6.96^{a}$ & 65 \\
$\mathrm{MoTe}_{2}$ & 351.14 & 100.4699 & $7.78^{\circ}$ & 78 \\
\hline
\end{tabular}

a Compare reference 3.

- Compare reference 4 .

by the intermittent adiabatic technique. Accuracy is assured by ultimately referring all determinations of mass, temperature, resistance, and potentials to calibrations performed by the National Bureau of Standards and by the measurement of heat capacity of standards established by the Calorimetry Conference. ${ }^{(5)}$

\section{SAMPLE PROVENANCE}

The samples of molybdenum diselenide and ditelluride were purchased from Alpha Inorganics and were claimed to be more than 99 moles per cent pure. Both were fine powders, had a black-gray metallic color, and were slippery to the touch. X-ray 
powder diffraction patterns for $\mathrm{MoTe}_{2}$ and $\mathrm{MoSe}_{2}$ were taken to characterize both as $\alpha$-phase (hexagonal). No impurities were detected; only two very weak extra lines were found and the deduced cell parameters agreed well with literature values. ${ }^{(6,7)}$

\section{Results}

The heat capacities were corrected for curvature. ${ }^{(8)}$ The results are expressed in terms of molar masses on the 1968 scale of atomic weights. The smoothed heat capacities and the thermodynamic functions, at selected temperatures, were obtained by fitting a polynomial through the experimental points by least squares and integrating the resulting functions. Below $5 \mathrm{~K}$ the heat capacities were extrapolated from a plot of $C_{p} / T$ against $T^{2}$ as depicted in figure 1.

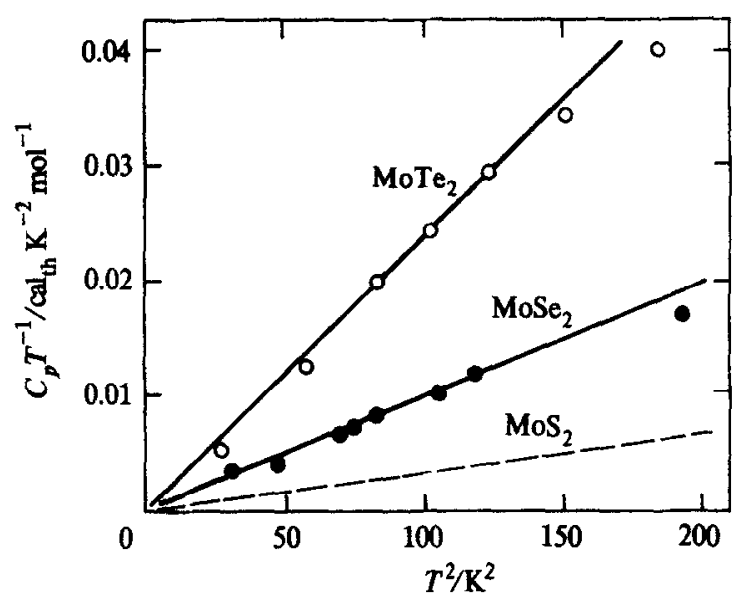

FIGURE 1. Plot of $C_{p} / T$ against $T^{2}$ for $\mathrm{MoS}_{2}, \mathrm{MoSe}_{2}$, and MoTe 2 .

The heat capacities at constant pressure, $C_{p}$, are presented in table 2 and depicted graphically in figure 2 . The thermodynamic functions obtained by digital computer quadrature are reported in tables 3 and 4 at selected temperatures.

It is to be noted that although the columns in tables 3 and 4 are headed as absolute quantities, the extrapolations between 0 and $5 \mathrm{~K}$ assume the absence of any anomalies in the heat capacity.

\section{Discussion}

The plots of $\log C_{p}$ against $\log T$ for $\mathrm{MoS}_{2}, \mathrm{MoSe}_{2}$, and $\mathrm{MoTe}_{2}$ in figure 3 all indicate that there is no region in which the low-temperature heat capacity is represented explicitly by a $T^{2}$ limiting law over a finite temperature range. Rather, for all three at the lowest temperatures an obvious trend to the usual Debye $T^{3}$-limiting law occurs. A short temperature range in each over which the tangent to the heat capacity curve 
TABLE 2. Heat capacities of molybdenum diselenide and ditelluride $\left(\mathrm{cal}_{\mathrm{th}}=4.184 \mathrm{~J}\right)$

\begin{tabular}{|c|c|c|c|c|c|c|c|}
\hline$\frac{T}{\mathrm{~K}}$ & $\frac{C_{p}}{\mathrm{cal}_{\mathrm{th}} \mathrm{K}^{-1} \mathrm{~mol}^{-1}}$ & $\frac{T}{\mathbf{K}}$ & $\frac{C_{p}}{\mathrm{cal}_{t \mathrm{n}} \mathrm{K}^{-1} \mathrm{~mol}^{-1}}$ & $\frac{T}{\mathrm{~K}}$ & $\frac{C_{p}}{\operatorname{cal}_{t h} \mathrm{~K}^{-1} \mathrm{~mol}^{-1}}$ & $\frac{T}{\mathrm{~K}} \overline{\mathrm{c}}$ & $\frac{C_{p}}{\mathrm{cal}_{\mathrm{th}} \mathrm{K}^{-\mathbf{1}} \mathrm{mol}^{-1}}$ \\
\hline \multicolumn{8}{|c|}{ Molybdenum diselenide $\left(\mathrm{MoSe}_{2}\right)$} \\
\hline & Series I & 211.26 & 15.37 & & Series IV & & Series V \\
\hline 62.29 & 5.221 & 221.37 & 15.62 & 10.92 & 0.130 & 8.661 & 10.064 \\
\hline 68.20 & 5.985 & 231.35 & 15.83 & 13.93 & 0.237 & 9.183 & 0.077 \\
\hline 74.00 & 6.709 & 241.22 & 16.02 & 15.13 & 0.288 & & \\
\hline 80.43 & 7.495 & 251.00 & 16.17 & 16.33 & 0.342 & & \\
\hline 87.40 & 8.323 & 261.42 & 16.36 & 17.61 & 0.399 & & \\
\hline 95.45 & 9.151 & 271.74 & 16.15 & 18.95 & 0.466 & \multicolumn{2}{|c|}{ Series VI } \\
\hline 105.49 & 10.09 & & & 20.44 & 0.550 & 5.55 & 0.078 \\
\hline 116.26 & 11.00 & & & 22.20 & 0.657 & 7.09 & $0.034^{a}$ \\
\hline 126.31 & 11.75 & \multirow{2}{*}{\multicolumn{2}{|c|}{ Series III }} & 24.07 & 0.783 & 8.26 & $0.055^{a}$ \\
\hline 136.10 & 12.40 & & & 25.79 & 0.913 & 9.30 & 0.083 \\
\hline & & 258.10 & 16.33 & 27.50 & 1.053 & 10.30 & 0.110 \\
\hline & Series II & 268.94 & 16.49 & 29.73 & 1.248 & 11.39 & 0.140 \\
\hline 138.82 & $\quad 12.58$ & 279.68 & 16.63 & 32.32 & 1.498 & 12.54 & 0.180 \\
\hline 149.53 & 13.18 & 290.33 & 16.76 & 35.45 & 1.827 & 37.39 & 2.040 \\
\hline 159.86 & 13.68 & 300.89 & 16.90 & 39.70 & 2.299 & 45.08 & 2.948 \\
\hline 170.11 & 14.10 & 311.37 & 17.02 & 44.52 & 2.877 & 49.61 & 3.532 \\
\hline 180.31 & 14.48 & 321.80 & 17.15 & 49.34 & 3.497 & 54.69 & 4.198 \\
\hline 190.61 & 14.80 & 332.15 & 17.26 & 54.84 & 4.218 & 60.60 & 4.988 \\
\hline 201.02 & 15.10 & 342.46 & 17.32 & 60.14 & 4.920 & & \\
\hline \multicolumn{8}{|c|}{ Molybdenum ditelluride $\left(\mathrm{MoTe}_{2}\right)$} \\
\hline & Series I & & Series II & 263.08 & 17.99 & 11.14 & 0.328 \\
\hline 56.99 & 7.533 & 178.23 & 16.33 & 273.12 & 18.09 & 12.35 & 0.421 \\
\hline 63.40 & 8.497 & 189.16 & 16.60 & 283.09 & 18.20 & 13.70 & 0.552 \\
\hline 70.65 & 9.442 & 199.92 & 16.85 & 293.00 & 18.32 & 15.28 & 0.714 \\
\hline 79.98 & 10.56 & 210.53 & 17.06 & 302.87 & 18.42 & 17.28 & 0.934 \\
\hline 89.63 & 11.58 & 221.02 & 17.28 & 312.68 & 18.53 & 19.57 & 1.223 \\
\hline 99.10 & 12.37 & 231.40 & 17.48 & 322.72 & $18.67^{a}$ & 21.91 & 1.553 \\
\hline 109.86 & 13.17 & 241.68 & 17.64 & 332.98 & $18.78^{a}$ & 24.31 & 1.920 \\
\hline 121.26 & 13.93 & 251.87 & 17.78 & 343.50 & 18.84 & 26.90 & 2.346 \\
\hline 132.08 & 14.55 & & & & & 29.93 & 2.871 \\
\hline 142.49 & 15.06 & & & & & 33.63 & 3.534 \\
\hline 152.94 & 15.51 & \multirow{2}{*}{\multicolumn{2}{|c|}{ Series III }} & \multicolumn{2}{|r|}{ Series IV } & 37.65 & 4.260 \\
\hline 163.70 & 15.88 & & & 5.27 & $\quad 0.021$ & 41.83 & 4.991 \\
\hline 174.78 & 16.22 & 222.14 & $\quad 17.29$ & 7.60 & 0.095 & 46.37 & 5.792 \\
\hline 185.96 & 16.51 & 232.51 & 17.48 & 8.14 & 0.145 & 51.75 & 6.700 \\
\hline 196.96 & 16.77 & 242.79 & 17.66 & 9.14 & 0.182 & 57.95 & 7.687 \\
\hline 207.80 & 17.02 & 252.97 & 17.83 & 10.06 & 0.256 & & \\
\hline
\end{tabular}

a These points were given less weight in fitting smooth curves. 


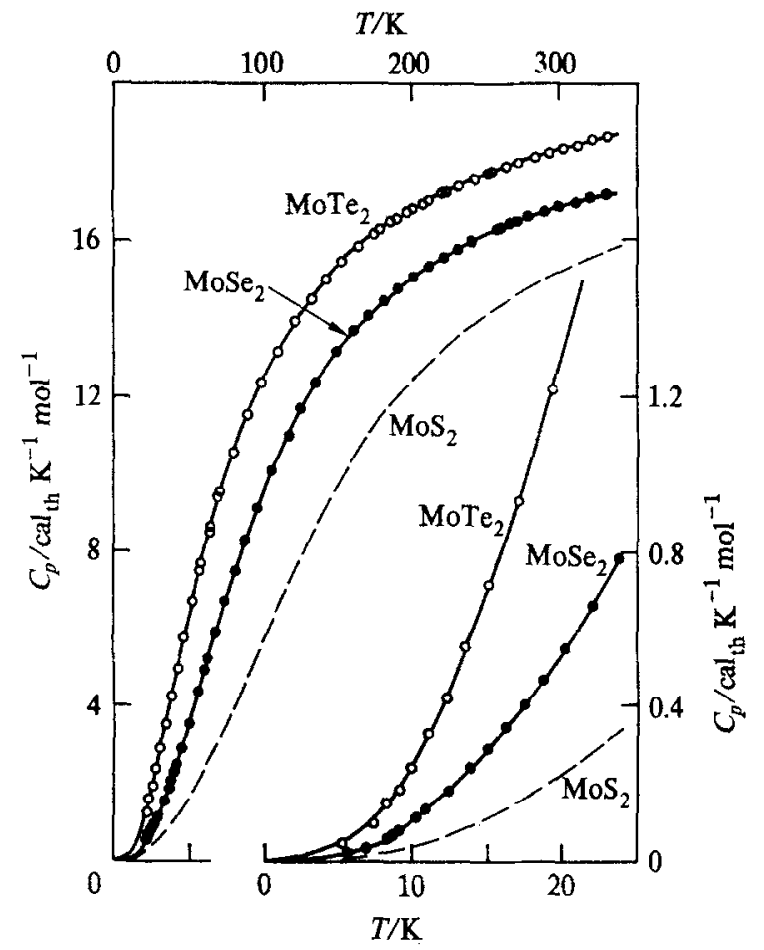

FIGURE 2. Molar heat capacities for $\mathrm{MoS}_{2}$ (from reference 1) $\mathrm{MoSe}_{2}$, and $\mathrm{MoTe}_{2}$. For this series of isostructural chalcogenides, the Mo cation has an atomic weight of 95.94; that of the anion varies from 32.06 for sulfur, to $\mathbf{7 8 . 9 6}$ for selenium, and to $\mathbf{1 2 7 . 6 0}$ for tellurium.

approximates proportionality to $T^{2}$ is found, but this region clearly gives way to a $T^{3}$ behavior as lower temperatures are approached.

Some observers insist that an inflexion exists between the $T^{2}$-region and the $T^{3}$ region of the logarithmic plots (shown in figure 3 ). Literature assertions for the existence of a $T^{2}$-limiting law for heat capacity have either been heavily based on theory, on experimental results of less than adequate quality, or on failure to extend the experimental results to sufficiently low temperatures to encounter the region of $T^{3}$ dependence. As has already been noted, the tendency of plotting $C_{p}$ against $T^{2}$ so minimizes the region of approach to $T \rightarrow 0$ that the authors are readily deluded toward erroneous conclusions.

So despite literature claims to the contrary, it has been shown that even for lamellar (sandwich-layer) molybdenum disulfide ${ }^{(1)}$ when measurements are made to temperatures as low as $5 \mathrm{~K}$, the $T^{2}$-proposal of Tarassov and others ${ }^{(9-12)}$ for the limiting law fails as lower temperatures are approached. This is in contrast with claims made on measurements which did not extend below $18 \mathrm{~K}$ on $\mathrm{MoS}_{2}$ and $\mathrm{MoO}_{3}{ }^{(13)}$ The present investigations on the higher chalcogenides totally confirm the recent conclusions $^{(1)}$ and this further study establishes these conclusions as being independent of accidental atomic mass ratios, etc. The same trends in heat capacity behavior 
TABLE 3. Thermodynamic functions of molybdenum diselenide $\left(\mathrm{cal}_{\mathrm{th}}=4.184 \mathrm{~J}\right)$

\begin{tabular}{|c|c|c|c|c|}
\hline$\frac{T}{\mathrm{~K}}$ & $\frac{C_{\mathrm{p}}}{\mathrm{cal}_{\mathrm{th}} \mathrm{K}^{-1} \mathrm{~mol}^{-1}}$ & $\frac{\left\{S^{\circ}(T)-S^{\circ}(0)\right\}}{\mathrm{cal}_{\mathrm{th}} \mathrm{K}^{-1} \mathrm{~mol}^{-1}}$ & $\frac{\left\{H^{\circ}(T)-H^{\circ}(0)\right\}}{\mathrm{cal}_{t h} \mathrm{~mol}^{-1}}$ & $\frac{-\left\{G^{\circ}(T)-H^{\circ}(0)\right\} / T}{\mathrm{cal}_{\mathrm{ch}} \mathrm{K}^{-1}} \frac{\mathrm{mol}^{-1}}{\mathrm{~mol}^{-1}}$ \\
\hline 5 & 0.0233 & 0.0078 & 0.0293 & 0.0020 \\
\hline 10 & 0.1002 & 0.0362 & 0.2563 & 0.0106 \\
\hline 15 & 0.2827 & 0.110 & 1.191 & 0.0301 \\
\hline 20 & 0.5244 & 0.222 & 3.179 & 0.0633 \\
\hline 25 & 0.8518 & 0.373 & 6.579 & 0.110 \\
\hline 30 & 1.275 & 0.564 & 11.857 & 0.169 \\
\hline 35 & 1.777 & 0.797 & 19.457 & 0.241 \\
\hline 40 & 2.336 & 1.070 & 29.718 & 0.328 \\
\hline 45 & 2.939 & 1.380 & 42.889 & 0.427 \\
\hline 50 & 3.580 & 1.723 & 59.173 & 0.539 \\
\hline 60 & 4.909 & 2.493 & 101.60 & 0.799 \\
\hline 70 & 6.212 & 3.348 & 157.25 & 1.101 \\
\hline 80 & 7.444 & 4.259 & 225.61 & 1.439 \\
\hline 90 & 8.577 & 5.202 & 305.81 & 1.804 \\
\hline 100 & 9.600 & 6.160 & 396.79 & 2.192 \\
\hline 110 & 10.51 & 7.118 & 497.43 & 2.596 \\
\hline 120 & 11.31 & 8.068 & 606.63 & 3.013 \\
\hline 130 & 12.02 & 9.002 & 723.37 & 3.437 \\
\hline 140 & 12.64 & 9.916 & 846.72 & 3.868 \\
\hline 150 & 13.18 & 10.81 & 975.88 & 4.301 \\
\hline 160 & 13.66 & 11.67 & 1110.1 & 4.735 \\
\hline 170 & 14.08 & 12.51 & 1248.9 & 5.168 \\
\hline 180 & 14.46 & 13.33 & 1391.6 & 5.598 \\
\hline 190 & 14.79 & 14.12 & 1537.9 & 6.026 \\
\hline 200 & 15.09 & 14.89 & 1687.3 & 6.450 \\
\hline 210 & 15.35 & 15.63 & 1839.6 & 6.870 \\
\hline 220 & 15.59 & 16.35 & 1994.3 & 7.284 \\
\hline 230 & 15.81 & 17.05 & 2151.3 & 7.694 \\
\hline 240 & 16.00 & 17.72 & 2310.4 & 8.098 \\
\hline 250 & 16.17 & 18.38 & 2471.2 & 8.496 \\
\hline 260 & 16.33 & 19.02 & 2633.8 & 8.888 \\
\hline 270 & 16.48 & 19.64 & 2797.9 & 9.275 \\
\hline 280 & 16.63 & 20.24 & 2963.4 & 9.656 \\
\hline 290 & 16.76 & 20.83 & 3130.4 & 10.031 \\
\hline 300 & 16.89 & 21.40 & 3298.6 & 10.400 \\
\hline 310 & 17.02 & 21.95 & 3468.2 & 10.764 \\
\hline 320 & 17.13 & 22.49 & 3639.0 & 11.122 \\
\hline 330 & 17.23 & 23.02 & 3810.8 & 11.475 \\
\hline 340 & 17.31 & 23.54 & 3983.5 & 11.822 \\
\hline 350 & 17.34 & 24.04 & 4156.8 & 12.164 \\
\hline 273.15 & 16.53 & 19.83 & 2849.9 & 9.396 \\
\hline 298.15 & 16.87 & 21.29 & 3267.4 & 10.332 \\
\hline
\end{tabular}


TABLE 4. Thermodynamic functions of molybdenum ditelluride $\left(\mathrm{cal}_{\mathrm{th}}=4.184 \mathrm{~J}\right)$

\begin{tabular}{|c|c|c|c|c|}
\hline$\frac{T}{\mathrm{~K}}$ & $\frac{C_{p}}{\mathrm{cal}_{\mathrm{th}} \mathrm{K}^{-1} \mathrm{~mol}^{-1}}$ & $\frac{\left\{S^{\circ}(T)-S^{\circ}(0)\right\}}{\mathrm{cal}_{\mathrm{th}} \mathrm{K}^{-1} \mathrm{~mol}^{-1}}$ & $\frac{\left\{H^{\circ}(T)-H^{\circ}(0)\right\}}{\text { cal }_{\text {tn }} \mathrm{mol}^{-1}}$ & $\frac{-\left\{G^{\circ}(T)-H^{\circ}(0)\right\} / T}{\mathrm{cal}_{\mathrm{th}} \mathrm{K}^{-1} \mathrm{~mol}^{-1}}$ \\
\hline 5 & 0.0176 & 0.0060 & 0.0225 & 0.0015 \\
\hline 10 & 0.244 & 0.0708 & 0.554 & 0.0154 \\
\hline 15 & 0.681 & 0.247 & 2.797 & 0.0602 \\
\hline 20 & 1.281 & 0.521 & 7.635 & 0.139 \\
\hline 25 & 2.031 & 0.885 & 15.859 & 0.251 \\
\hline 30 & 2.883 & 1.329 & 28.113 & 0.392 \\
\hline 35 & 3.774 & 1.840 & 44.740 & 0.562 \\
\hline 40 & 4.676 & 2.403 & 65.866 & 0.756 \\
\hline 45 & 5.562 & 3.005 & 91.471 & 0.973 \\
\hline 50 & 6.416 & 3.636 & 121.43 & 1.207 \\
\hline 60 & 7.992 & 4.948 & 193.63 & 1.721 \\
\hline 70 & 9.370 & 6.286 & 280.61 & 2.277 \\
\hline 80 & 10.56 & 7.617 & 380.40 & 2.862 \\
\hline 90 & 11.58 & 8.920 & 491.20 & 3.463 \\
\hline 100 & 12.45 & 10.19 & 611.46 & 4.072 \\
\hline 110 & 13.21 & 11.41 & 739.88 & 4.684 \\
\hline 120 & 13.87 & 12.59 & 875.37 & 5.294 \\
\hline 130 & 14.44 & 13.72 & 1017.0 & 5.899 \\
\hline 140 & 14.94 & 14.81 & 1164.0 & 6.497 \\
\hline 150 & 15.37 & 15.86 & 1315.6 & 7.086 \\
\hline 160 & 15.75 & 16.86 & 1471.2 & 7.666 \\
\hline 170 & 16.07 & 17.83 & 1630.3 & 8.235 \\
\hline 180 & 16.36 & 18.75 & 1792.6 & 8.794 \\
\hline 190 & 16.62 & 19.64 & 1957.5 & 9.342 \\
\hline 200 & 16.85 & 20.50 & 2124.9 & 9.879 \\
\hline 210 & 17.07 & 21.33 & 2294.5 & 10.404 \\
\hline 220 & 17.26 & 22.13 & 2466.1 & 10.919 \\
\hline 230 & 17.44 & 22.90 & 2639.6 & 11.423 \\
\hline 240 & 17.61 & 23.65 & 2814.9 & 11.917 \\
\hline 250 & 17.77 & 24.37 & 2991.9 & 12.401 \\
\hline 260 & 17.92 & 25.07 & 3170.3 & 12.875 \\
\hline 270 & 18.05 & 25.75 & 3350.1 & 13.339 \\
\hline 280 & 18.17 & 26.41 & 3531.3 & 13.794 \\
\hline 290 & 18.29 & 27.05 & 3713.6 & 14.240 \\
\hline 300 & 18.40 & 27.67 & 3897.1 & 14.677 \\
\hline 310 & 18.51 & 28.27 & 4081.6 & 15.106 \\
\hline 320 & 18.61 & 28.86 & 4267.3 & 15.527 \\
\hline 330 & 18.70 & 29.44 & 4453.9 & 15.940 \\
\hline 340 & 18.79 & 30.00 & 4641.3 & 16.345 \\
\hline 350 & 18.87 & 30.54 & 4829.6 & 16.743 \\
\hline 273.15 & 18.09 & 25.96 & 3407.0 & 13.483 \\
\hline 298.15 & 18.38 & 27.55 & 3863.0 & 14.597 \\
\hline
\end{tabular}




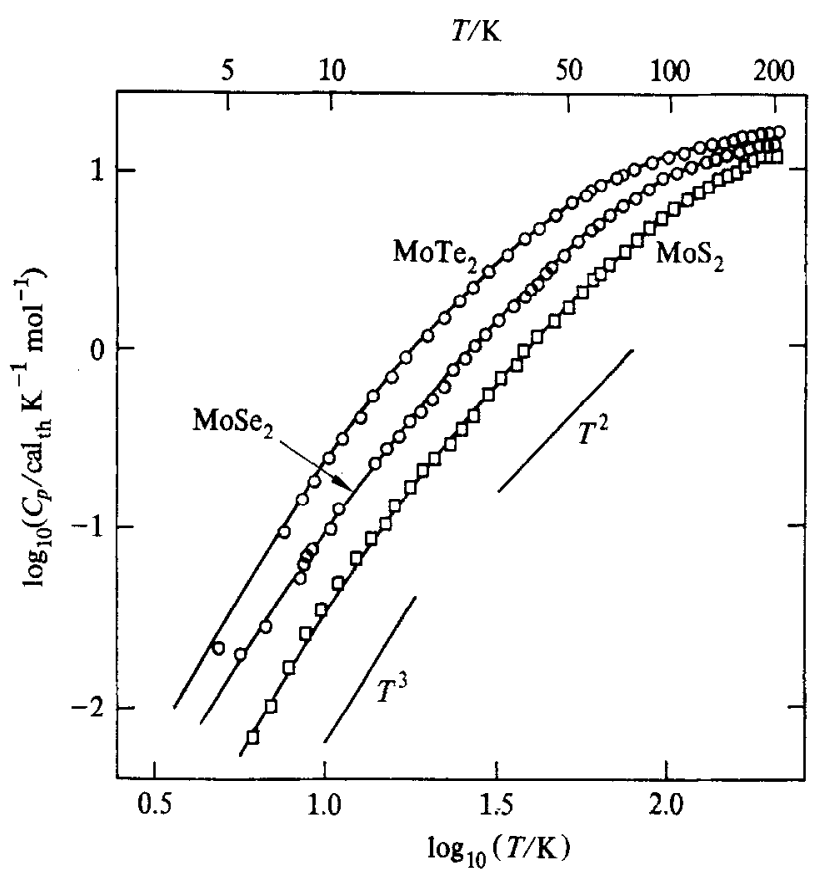

FIGURE 3. Plot of $\log _{10} C_{p}$ against $\log _{10} T$ for $\mathrm{MoS}_{9}, \mathrm{MoSe}_{2}$, and MoTe $\mathrm{M}_{2}$.

with increasing temperature from $T^{3}$ through $T^{2}$ toward $T^{1}$ and perhaps nearly to $T^{0}$ behavior are to be expected to obtain generally. Hence, Newells' theoretical analysis $^{(14)}$ is substantially correct.

For material related to the structures, physical properties, and related details on $\mathrm{MoS}_{2}$ and $\mathrm{MoTe}_{2}$ supplementary material deposited elsewhere ${ }^{(15)}$ may be consulted.

We acknowledge with gratitude the continuing support of the National Science Foundation and the provision of a fellowship for one of us (H.L.K.) by the Rockefeller Foundation.

\section{REFERENCES}

1. McBride, J. J.; Westrum, E. F., Jr. To be published.

2. Westrum, E. F., Jr.; Furukawa, G. T.; McCullough, J. P. In Experimental Thermodynamics, Vol. 1. McCullough, J. P.; Scott, D. W.; editors. Butterworths: London. 1968.

3. Brixner, L. H. J. Inorg. Nucl. Chem. 1962, 24, 257.

4. Knop, O.; MacDonald, R. D. Can. J. Chem. 1961, 30, 897.

5. Furukawa, G. T.; McCoskey, R. E.; King, G. J. J. Res. Nat. Bur. Stand. 1951, 47, 256.

6. James, P. B.; Lavik, M. T. Acta Cryst. 1963, 16, 1183.

7. Puotinen, D.; Newnham, R. E. Acta Cryst. 1961, 14, 691.

8. Westrum, E. F., Jr. J. Chem. Educ. 1962, 39, 443.

9. Tarasov, V. V. Dokl. Akad. Nauk S.S.S.R. 1945, 46, 22. Ibid. 1947, 58, 577, and numerous other studies.

10. Lifshits, I. M. Zh. Eksp. Teor. Fiz. 1952, 22, 471.

11. DeSorbo, W.; Tyler, W. W. J. Chem. Phys. 1953, 21, 1660.

12. Bergenlid, U.; Hill, R. W.; Webb, F. J.; Wilks, J. Phil. Mag. 1954, 45, 851. 
13. Smith, D. F.; Brown, D.; Dworkin, A. S.; Sasmor, D. J.; Van Artsdalen, E. R. J. Amer. Chem. Soc. 1956, 78, 1533.

14. Newell, G. F. "Specific Heat of Lamellar Crystals", Technical Report, Metals Laboratory, Brown University, Contract No. NONR-562 (08). 1954.

Ibid. "Vibration Spectrum of Graphite and Boron Nitride, I. The Two-Dimensional Spectrum". 1955.

15. For supplementary material including adjuvant, structural and physical properties of the substances reported in this paper and derived thermodynamics of chemical reactions made possible by the new data order NAPS document No. 02546 for 45 pages of supplementary material. Order from ASIS/NAPS c/o Microfiche Publications, 305 E. 46th St., New York, N.Y. 10017. Remit in advance for each NAPS accession number. Make checks payable to Microfiche Publications. Photocopies are \$7.25. Microfiche are \$1.50. Outside of the U.S. or Canada, postage is $\$ 2.00$ for a PC or $\$ 0.50$ for a fiche. 